\title{
Cafeína: un nutriente, un fármaco, o una droga de abuso
}

\author{
Ricardo Pardo lozano*; Yolanda Alvarez García**; Diego Barral Tafalla**; \\ Magí Farré Albaladejo*** \\ * Médico residente de Farmacología Clínica, Unidad de Farmacología. IMIM-Hospital del Mar, Barcelona y Universidad Autónoma de Barcelona. \\ * Médico especialista en Farmacología Clínica. \\ *** Consultor-2, Unidad de Farmacología. IMIM-Hospital del Mar, Barcelona y Profesor Titular, Universidad Autónoma de Barcelona.
}

Enviar correspondencia a:

Magí Farré. IMIM-Hospital del Mar, Edificio PRBB, Calle del Doctor Aiguader 88 - 08003 Barcelona. Tel. 933 160400; Fax 933160410; correo-e: mfarre@imim.e

\section{RESUMEN}

El café, el té, el chocolate y los refrescos de cola son las principales fuentes de cafeína, que es consumida en casi todas las edades y estratos socioeconómicos. La cafeína es un antagonista competitivo de los receptores adenosínicos del SNC. Sus principales efectos son psicoestimulantes, respiratorios, músculo-esqueléticos y cardiovasculares. Básicamente, se metaboliza por el CYP1A2 por lo que interacciona con numerosos fármacos. Las variaciones interindividuales en su metabolismo explican las diferencias de sus efectos. Su principal uso terapéutico es como broncodilatador en patología respiratoria. Además, se ha experimentado en otras patologías con resultados no concluyentes. El consumo agudo o crónico de cafeína puede dar lugar a una amplia variedad de efectos adversos, intoxicaciones e incluso la muerte. Finalmente, destacar que la cafeína puede considerarse una droga de abuso. Así, la cafeína posee propiedades reforzadoras positivas, produce tolerancia y al cesar su consumo aparece un síndrome de abstinencia específico. La cafeína puede dar lugar a diferentes trastornos por uso de sustancias. Entre ellas la dependencia, no reconocida en el DSM IV-R, el síndrome de abstinencia y la intoxicación. La cafeína puede considerarse un fármaco, un nutriente y una droga de abuso dependiendo de su uso.

Palabras clave: Cafeina, dependencia, droga de abuso, intoxicación, reacciones adversas, farmacocinética.

\begin{abstract}
Coffee, tea, chocolate and caffeinated drinks are the main sources of caffeine, which is consumed in almost all ages and socioeconomic levels. Caffeine acts as a non-selective adenosine receptor antagonist in the central nervous system. Its main effects are as psychostimulant, acting in addition on the respiratory, muscular and cardiovascular systems. Basically, caffeine is metabolized by the hepatic cytochrome P-450 1A2 enzymes (CYP1A2). Several drugs can interact with its metabolism. The observed interindividual differences of its effects can be explained by variations in its metabolism. The main therapeutic use of caffeine is bronchodilator in respiratory diseases. Other possible uses are under investigation. Acute or chronic consumption of caffeine can induce several adverse effects, including intoxication that can be lethal. Finally, caffeine can be considered a drug of abuse. It has positive reinforcing actions, produces tolerance, and a withdrawal syndrome after stopping its consumption. Caffeine can cause different mental disorders such as dependence, which is not included in the DSM-IV-R, withdrawal syndrome and intoxication. Depending on its use, caffeine can be considered a nutrient, a drug or a drug of abuse.
\end{abstract}

Key words: Caffeine, drug dependence, drug of abuse, intoxication, adverse event, pharmacokinetics.
$\mathbf{L}$ a cafeína, también denominada teína, guaranina o mateína, es un constituyente natural presente en más de 60 especies de plantas. Se encuentra en la dieta diaria contenida en bebidas como el café o el té, el chocolate y algunos refrescos. Se podría considerar la sustancia estimulante de mayor consumo y la más socialmente aceptada a nivel mundial.

Historia. La cafeína ha sido consumida durante siglos a pesar de los intentos repetidos de prohibir su uso por motivos morales, económicos, médicos o políticos. El descubrimiento del café tuvo lugar en el siglo
IX en Arabia. Se cultivó por primera vez en Etiopía, de la misma forma que el té en China y el cacao en América del Sur. En el siglo XV se desarrolló la técnica de tostar y moler los granos de café y el consumo de los productos con cafeína se expandió rápidamente por todo el mundo. Las especies económicamente más importantes de café son la Coffea arabica (café arábigo) y la Coffea canephora (café robusta) que suponen el $80-90 \%$, el 10-20\% de la producción mundial respectivamente ${ }^{1-3}$. 
Propiedades físico-químicas. La cafeína es un polvo inodoro, incoloro y amargo. Friedrich Ferdinand Runge la aisló del café en 1819 y del té en 1827, pero su estructura química no se describió hasta 1875 por E. Fischer. La cafeína (1,3,7-trimetilxantina) y los otros alcaloides metilxantínicos, como la teobromina (3,7dimetilxantina) y la teofilina (1,3-dimetilxantina), son derivados del grupo de las xantinas, que a su vez se derivan de las purinas. Se relacionan farmacológicamente con los psicoestimulantes ${ }^{1-3}$.

\section{PRINCIPALES FUENTES}

El café es la semilla madura desecada de la planta. El café es el producto que contiene la cantidad más alta y variable de cafeína en la dieta (0.8-1.8\%). La dosis de cafeína del café depende de las diferencias genéticas de los granos así como del tiempo y la forma de preparación (ver Tabla 1), oscilando entre 30 y $175 \mathrm{mg}$ por $150 \mathrm{ml}$. El café descafeinado contiene entre 2 y $8 \mathrm{mg}$ por $150 \mathrm{ml}$.
El té es el segundo producto en contenido de cafeína. Es la hoja desecada del arbusto Camellia o Thea sinensis, bohea o viridis. Además, se encuentra en menor cantidad la teofilina (hoja divina, en griego). Básicamente, existen cuatro tipos de té: el verde (no fermentado), el té rojo (semifermentado), el té negro (fermentado) y el té blanco. La concentración oscila entre 20-73 mg /100 ml según el método de elaboración y el tiempo de extracción.

El cacao es la semilla desecada y fermentada de la Theobroma (alimento de los dioses, en griego) cacao ('Ka'kaw, árbol del cacao en maya). En el cacao predomina la teobromina $(2,5 \%)$ y en menor cantidad la cafeína $(0,4 \%)$. El contenido de cafeína del chocolate oscila entre 5-20 mg/100g y depende del lugar de procedencia del cacao. El chocolate negro, amargo o semidulce posee mucha más cafeína que en el chocolate con leche. El chocolate contiene además anandamida que es un ligando endógeno de los receptores cannabinoides.

Las plantas como la guaraná (pasta desecada de las semillas de Paullina cupana), el mate (hoja dese-

Tabla 1 Principales fuentes de cafeína.

\begin{tabular}{|c|c|c|c|}
\hline & Volumen / Peso & $\begin{array}{c}\text { Contenido cafeína } \\
\text { (rango) }\end{array}$ & $\begin{array}{l}\text { Contenido cafeína } \\
\text { (promedio) }\end{array}$ \\
\hline \multicolumn{4}{|l|}{ Café } \\
\hline tostado & $150 \mathrm{ml}$ & $64-124 \mathrm{mg}$ & $83 \mathrm{mg}$ \\
\hline instantáneo & $150 \mathrm{ml}$ & $40-108 \mathrm{mg}$ & $59 \mathrm{mg}$ \\
\hline tostado descafeinado & $150 \mathrm{ml}$ & $2-5 \mathrm{mg}$ & $3 \mathrm{mg}$ \\
\hline instantáneo descafeinado & $150 \mathrm{ml}$ & $2-8 \mathrm{mg}$ & $4 \mathrm{mg}$ \\
\hline tostado de goteo & $150 \mathrm{ml}$ & $37-148 \mathrm{mg}$ & $84 \mathrm{mg}$ \\
\hline todos los cafés excepto descafeinado & $150 \mathrm{ml}$ & $29-176 \mathrm{mg}$ & \\
\hline \multicolumn{4}{|l|}{ Té } \\
\hline té & $150 \mathrm{ml}$ & $8-91 \mathrm{mg}$ & $27 \mathrm{mg}$ \\
\hline bolsa de té & $150 \mathrm{ml}$ & $28-44 \mathrm{mg}$ & $30 \mathrm{mg}$ \\
\hline hoja de té & $150 \mathrm{ml}$ & $30-48 \mathrm{mg}$ & $41 \mathrm{mg}$ \\
\hline té instantáneo & $150 \mathrm{ml}$ & $24-31 \mathrm{mg}$ & $28 \mathrm{mg}$ \\
\hline \multicolumn{4}{|l|}{ Cacao } \\
\hline cacao africano o sudamericano & $150 \mathrm{ml}$ & & $6 \mathrm{mg}$ \\
\hline cacao & $150 \mathrm{ml}$ & & $42 \mathrm{mg}$ \\
\hline tableta chocolate & $28 \mathrm{~g}$ & & $20 \mathrm{mg}$ \\
\hline chocolate con leche & $28 \mathrm{~g}$ & $1-15 \mathrm{mg}$ & $6 \mathrm{mg}$ \\
\hline chocolate dulce & $28 \mathrm{~g}$ & $1,5-6 \mathrm{mg}$ & $3 \mathrm{mg}$ \\
\hline leche con chocolate & $240 \mathrm{ml}$ & $2-7 \mathrm{mg}$ & $5 \mathrm{mg}$ \\
\hline chocolate a la taza & $28 \mathrm{~g}$ & $18-118 \mathrm{mg}$ & $60 \mathrm{mg}$ \\
\hline \multicolumn{4}{|l|}{ Bebidas } \\
\hline colas & $180 \mathrm{ml}$ & $15-35 \mathrm{mg}$ & \\
\hline colas descafeinadas & $180 \mathrm{ml}$ & $0 \mathrm{mg}$ & \\
\hline colas light & $180 \mathrm{ml}$ & $13-35 \mathrm{mg}$ & \\
\hline colas light descafeinadas & $180 \mathrm{ml}$ & $0 \mathrm{mg}$ & \\
\hline
\end{tabular}


cada de la hierba Ilex paraguayensis), la cola (semilla desecada de Cola nitida) y el yoco también contienen cafeína (2-4\%).

Los refrescos con cafeína, incluidos los etiquetados como diet o light, presentan entre 15-35 mg/180 $\mathrm{ml}$ de cafeína. Sólo un 5\% de refrescos están libres de cafeína. Las bebidas energéticas presentan mayor contenido en cafeína que los refrescos. Por ejemplo el Red Bull $\circledast$ contiene 80 mg de cafeína en $250 \mathrm{ml}$.

Algunos medicamentos también contienen cafeína, generalmente en combinación con otros principios activos, ya sean los que no requieren prescripción médica (OTC, over the counter) o los de prescripción. Los contenidos oscilan habitualmente entre 15 y 200 mg, siendo mayor la dosis en los que no precisan receta. Existen medicamentos en los que el único principio activo es la cafeína a dosis elevadas (hasta $300 \mathrm{mg})^{1-5}$

\section{EPIDEMIOLOGÍA DEL CONSUMO}

El café representa el principal aporte de cafeína dentro de la dieta del adulto en países como los EEUU, Finlandia, Suecia, Dinamarca y Suiza. En España se estima que el $80 \%$ de la población adulta tiene un consumo medio de cafeína de entre 200-300 mg por persona y día (2-3 tazas de café). En niños menores de 18 años, la ingesta media es de $1 \mathrm{mg} / \mathrm{kg} / \mathrm{día}$ y las principales fuentes de cafeína son los refrescos y el chocolate. Hace unos años, la Food and Drug Administration (FDA) de los EEUU limitó la cantidad de cafeína en las bebidas carbónicas a $0.2 \mathrm{mg} / \mathrm{mL}$, por considerarla una sustancia con potencial adictivo y ser una fuente importante de cafeína en todas las edades ${ }^{1}$. Aún así, existen numerosos productos destinados a los niños (refrescos, helados, caramelos) que contienen cafeína sin ser especificada en la etiqueta. La FDA sólo obliga a indicar la cantidad de cafeína en el etiquetado del producto cuando se añade de forma intencionada.

En el 2003 se aprobó una nueva normativa europea, que amplia la directiva 2002/67/CE, en la que las bebidas, sobre todo las energéticas, con un contenido superior a $150 \mathrm{mg} / \mathrm{L}$ de cafeína deberán especificarlo en las etiquetas porque es una información necesaria para niños y embarazadas ${ }^{6}$.

Las bebidas energéticas están bajo control en algunos países. Así, en el 2004, en Francia, Dinamarca y Noruega sólo se podía adquirir Red Bull en las farmacias por su alto contenido en cafeína y los peligros que ello comporta. Se ha relacionado esta bebida con al menos cuatro fallecidos, un irlandés en el 2000 y tres suecos en el 2001. En dos de ellos se asoció al consumo de alcohol y en los otros dos con una actividad física intensa. La prohibición de su venta en Francia se justifica por las posibles interacciones entre los ingredientes (cafeína, taurina que es un aminoácido y glucurolactona, un carbohidrato), y el resultado de experimentos en ratones en los que tras ingerir taurina aparecieron, ansiedad, irritabilidad, sensibilidad al ruido y automutilaciones. Se cree que alto contenido en cafeína podría provocar una deshidratación en el consumidor que realiza un ejercicio físico intenso. En 2001 en Suecia se recomendó a sus consumidores no ingerir Red Bull con alcohol ni después de un ejercicio físico intenso. En cambio, el Reino Unido, donde Red Bull es líder de ventas, no ha realizado ninguna investigación ni está prevista una limitación en su venta por considerarlo seguro, a pesar que podría disminuir la presión arterial ${ }^{7}$. En el 2006, se publicó un ensayo clínico en el se concluye que la ingesta de una bebida energética disminuye las sensaciones subjetivas de intoxicación alcohólica, pero no reduce los déficits motores y visuales causados por el alcohol ${ }^{8}$.

\section{MECANISMO DE ACCIÓN}

Las metilxantinas (cafeína, teofilina y teobromina) por su semejanza a las purinas se unen a los receptores A1 y A2a de la adenosina, actuando como antagonistas competitivos (concentraciones de 10-40 micromolar/L). Esto produce una inhibición de la fosfodiesterasa que da lugar a un aumento de las concentraciones de AMPc y de GMPc, una activación de canales de $\mathrm{K}+\mathrm{y}$ una inhibición de los canales de calcio de tipo N. En cerebro los receptores de adenosina inhiben la liberación de numerosos neurotransmisores (GABA, acetilcolina, dopamina, glutamato, noradrenalina y serotonina), la cafeína producirá el efecto contrario. Los receptores A2a se coexpresan con receptores de encefalina y dopamina D2 en las neuronas del estriado. La cafeína potencia la neurotransmisión dopaminérgica en esa área cerebral y en parte podría explicar su potencial de abuso. Además, la cafeína actúa a concentraciones mucho mayores de las que antagonizan la adenosina como inhibidor directo de la fosfodiesterasa (400 micromol/L) ${ }^{9-11}$.

\section{EFECTOS FARMACOLÓGICOS}

Las metilxantinas tienen efectos comunes, aunque de intensidad variable. Por orden de potencia son la teofilina, la cafeína y por último la teobromina. A con- 
tinuación se describen los principales efectos de las metilxantinas, principalmente de la cafeína, en los diferentes aparatos y sistemas 1, 4, 5, 9, 10, 12, 13 .

\section{Sistema nervioso central}

Psicoestimulantes. La cafeína produce de forma dosis dependiente una activación generalizada del SNC, posiblemente al aumentar la liberación de noradrenalina ${ }^{11}$. Aumenta la alerta, Reduce la sensación de cansancio y fatiga, aumenta la capacidad de mantener un esfuerzo intelectual y mantiene el estado de vigilia a pesar de la privación de sueño ${ }^{14}$. Además, mediante la inhibición de los receptores A2, la cafeína tiene una acción reforzante mediante la liberación de dopamina en el circuito cerebral de recompensa (sistema mesolímbico y nucleus accumbens). Esta acción se explicaría por un aumento de la fosforilación del DARPP-32 (fosfoproteina de la regulación de dopamina y $A M P c){ }^{15}$.

Efectos analgésicos. La cafeína tiene un efecto analgésico dosis-dependiente potenciado por los inhibidores de la serotonina y un efecto adyuvante en la analgesia ${ }^{16}$.

\section{Respiratorios}

La metilxantinas estimulan el centro respiratorio y son broncodilatadoras. La teofilina es la más utilizada clínicamente a pesar de presentar un margen terapéutico estrecho y provocar los efectos adversos más graves. La cafeína mejora discretamente la función respiratoria al aumentar la contractilidad del diafragma ${ }^{17}$.

\section{Cardiovasculares}

La administración de cafeína provoca un aumento de la presión arterial ${ }^{18}$ y tiene un efecto cronotrópico e inotrópico positivo por inhibición de los receptores adenosínicos cardiacos, resultando en un aumento de la frecuencia cardiaca. En cambio, el chocolate a dosis bajas induce la formación de óxido nítrico y disminuye la presión arterial ${ }^{19}$. La cafeína no induce o empeora la severidad de las arritmias ventriculares y no aumenta el riesgo de fibrilación auricular ni flutter, excepto a dosis muy elevadas ${ }^{20}$. La teofilina $y$, en menor grado, las otras metilxantinas estimulan la contractilidad cardiaca de forma más rápida que la digital y más prolongada que los beta-adrenérgicos. Las metilxantinas producen vasoconstricción a nivel cerebra ${ }^{10}$.

\section{Músculoesqueléticos}

La cafeína es la metilxantina más activa para mejorar el rendimiento físico porque produce vasodilatación a nivel muscular, aumenta la respuesta contráctil al estímulo nervioso y disminuye el cansancio y la fatiga $10,11,13$
Dopaje. La cafeína fue durante años una sustancia restringida en el deporte y se consideró "doping" si se sobrepasaban los $12 \mathrm{mcg} / \mathrm{mL}$ en orina. Para dar positivo sería necesario ingerir unas 7 u 8 tazas de café y recoger una muestra a las 2-3 horas. En las listas de sustancias prohibidas en el deporte desde 2004 ya no consta como prohibida y por ello puede consumirse sin limitaciones.

\section{Otros efectos (endocrinos, digestivos y otros)}

La cafeína provoca un aumento dosis-dependiente del colesterol total, HDL, LDL y de los triglicéridos ${ }^{21}$, aunque parece que este incremento no es clínicamente relevante ${ }^{22}$. Existen resultados contradictorios del efecto que produce la cafeína sobre la sensibilidad a la insulina ${ }^{23}$, mientras que otros argumentan que esos efectos podrían deberse a otras sustancias del café ${ }^{24}$.

La cafeína estimula las contracciones de la vesícula biliar, relaja la musculatura lisa de las vías biliares, disminuye los niveles de colesterol en la bilis ${ }^{24}$ y estimula la secreción ácida gástrica ${ }^{9,11}$. La cafeína tiene un efecto diurético con tolerancia a largo plazo ${ }^{9,11}$. Se ha encontrado relación positiva no significativa entre altas dosis de cafeína y aumento de la presión intraocular en pacientes con glaucoma ${ }^{26}$. La cafeína y el chocolate podrían disminuir la agregabilidad plaquetaria ${ }^{27}$.

\section{Fertilidad y embarazo}

La cafeína es uno de los factores de riesgo para la subfertilidad en hombres y mujeres ${ }^{28}$, junto con el tabaco y las drogas recreacionales ${ }^{29}$. El consumo moderado de cafeína no aumenta el riesgo de aborto espontáneo ${ }^{30}$, no disminuye el crecimiento y no provoca microcefalia ${ }^{31}$. Pero altos niveles de cafeína, a diferentes dosis ${ }^{32}$, antes y durante el embarazo ${ }^{33}$ aumenta el riesgo de aborto espontáneo en no fumadoras ${ }^{34}$. Además, si el alto consumo se asocia a una alta actividad del CYP1A2 aumenta la probabilidad de abortos recurrentes ${ }^{35}$. La ingesta elevada de cafeína en forma de café, té, chocolate o colas durante el tercer trimestre del embarazo podría disminuir el crecimiento fetal ${ }^{36}$. No queda claro si la cafeína induciría partos prematuros ${ }^{37} \mathrm{O} \mathrm{no}^{38}$.

\section{FARMACOCINÉTICA}

La cafeína se absorbe por el tracto intestinal de forma rápida y completa, presentando una biodisponibilidad del $100 \%$. El tiempo en el que se alcanza la máxima concentración plasmática $\left(T_{\text {máx }}\right)$ es de 30-45 minutos en ayunas y se prolonga con la ingesta de alimentos. 
Tiene un volumen de distribución de 0.6-0.7 L/ $\mathrm{kg}$, Atraviesa la barrera hematoencefálica y la placentaria, también pasa a la leche materna, saliva, bilis y semen. La determinación en saliva ha sido usada como alternativa no invasiva para la monitorización de la concentración plasmática de la cafeína y teofilina. La fracción de cafeína unida a las proteínas plasmáticas, sobre todo a la albúmina, varía entre el $10-35 \%$, y podría disminuir en ancianos ${ }^{9,11 .}$

Las grandes diferencias interindividuales observadas en la concentración plasmática de cafeína tras la administración de una misma dosis se deben principalmente a las variaciones en el metabolismo. Estas variaciones dependen de cuatro factores: polimorfismos genéticos, inducción e inhibición metabólicas del citocromo P-450, individuales (peso y género) y la existencia de enfermedades hepáticas.

La cafeína presenta una cinética de eliminación de tipo Michaelis-Menten, resultando en una farmacocinética no lineal a dosis altas por saturación enzimática. El isoenzima del citocromo P-450 (CYP) hepático, subfamilia 1A, gen 2 (CYP1A2) metaboliza por desmetilación la mayoría de cafeína (95\%), transformándola en paraxantina (85\%), teobromina (10\%) y teofilina (5\%) (Figura 1). Posteriormente se metaboliza también por la CYP1A2 en monoxantinas, que serán sustrato de la xantinaoxidasa. La $\mathrm{N}$-acetiltransferasa-2 metaboliza la paraxantina a AFMU. Intervienen de forma minoritaria otras enzimas como la CYP2E1, y CYP3A3. Se ha descrito hasta 25 metabolitos. Sólo entre un 1-2\% de la dosis ingerida de cafeína se excreta sin cambios en orina ${ }^{39}$. La cafeína se considera el substrato prototipo y marcador del fenotipo metabolizador del CYP1A2 (razón paraxantina/cafeína) en plasma y saliva ${ }^{40}$. En

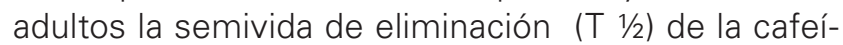
na es de 3-5 horas. En los recién nacidos, tanto el metabolismo como la tasa de depuración de cafeína están disminuidos y no alcanzan los niveles del adulto hasta los 6 y 3 meses respectivamente, la T 1/2 llega a alcanzar las 100 horas. En recién nacidos la teofilina se metaboliza en cafeína. En adultos, los fumadores presentan una T $1 / 2$ menor que los no fumadores. En personas no consumidoras de café la T $1 / 2$ de la cafeína se duplica, lo cual explica la mayor incidencia de intoxicación y severidad en individuos que no consumen habitualmente café $1,10,11,39$.

\section{INTERACCIONES FARMACOLÓGICAS}

\section{Farmacocinéticas}

Las concentraciones de cafeína pueden disminuir si se induce su metabolismo (CYP1A2). Entre los inductores se incluyen el humo del tabaco, la carne carbonizada, algunos vegetales crucíferos (el brócoli y la col de Bruselas), un bajo índice de masa corporal, el género masculino y el propio consumo de café (no se menciona). Así como tras la administración de rifampicina y omeprazol. El tabaco induce el metabolismo de la cafeína y en consecuencia disminuye sus niveles plasmáticos. Los fumadores que consumen café y abandonan el hábito de fumar pueden doblar las concentraciones plasmáticas de cafeína pudiendo presentar síntomas de intoxicación 2, 39, 41,42.

Las concentraciones de cafeína pueden aumentar si se inhibe su metabolismo. Destacan en este aspecto algunos procesos fisiológico/patológicos (final del embarazo, enfermedad hepática, obesidad, género femenino), alimentos (zumo de pomelo), alcohol y fármacos. Entre estos cabe mencionar los antimicóticos (fluconazol, ketoconazol), antiarrítmicos (diltiazem, verapamil), antidepresivos (paroxetina, fluoxetina, fluvoxamina), antipsicóticos (clozapina, olanzapina), metilxantinas (teofilina), anticonceptivos orales, cimetidina, fenilpropanolamina, psoralenos, quinolonas y alopurinol ${ }^{39,41}$.

La cafeína aumenta la absorción y biodisponibilidad de paracetamol, ácido acetilsalicílico y ergotamina y por lo tanto su efecto analgésico. Contrariamente, la cafeína disminuye la depuración de la teofilina e inhibe de forma competitiva el metabolismo de la clozapina pudiendo aumentar sus concentraciones plasmáticas y la probabilidad de aparición de efectos adversos. ${ }^{43}$

\section{Farmacodinámicas}

La cafeína produce efectos analgésicos aditivos cuando se administra con otros analgésicos, especialmente los AINE. La cafeína puede disminuir el efecto sedante de dosis bajas de barbitúricos y benzodiazepinas. Existe la creencia popular de que el café puede reducir los efectos deletéreos del alcohol. Los resultados son contradictorios, en algunos estudios se reduce la sensación de borrachera pero el rendimiento psicomotor no mejora, en otros mejoran ambos parámetros y finamente en otros la cafeína no modifica la intoxicación por alcohol ${ }^{39,41 .}$ En combinación con paroxetina o amoxapina puede provocar el síndrome serotoninergico ${ }^{44}$. Potencia los efectos de reforzamiento y estimulantes de la nicotina ${ }^{45}$, pero no altera el éxito de abstinencia de nicotina en el primer año de tratamiento ${ }^{46}$. Puede potenciar los efectos teratogénicos del alcohol, nicotina y vasoconstrictores ${ }^{47}$.

\section{REACCIONES ADVERSAS AGUDAS}

Debido a la gran variabilidad interindividual, una misma dosis de cafeína puede provocar reacciones 


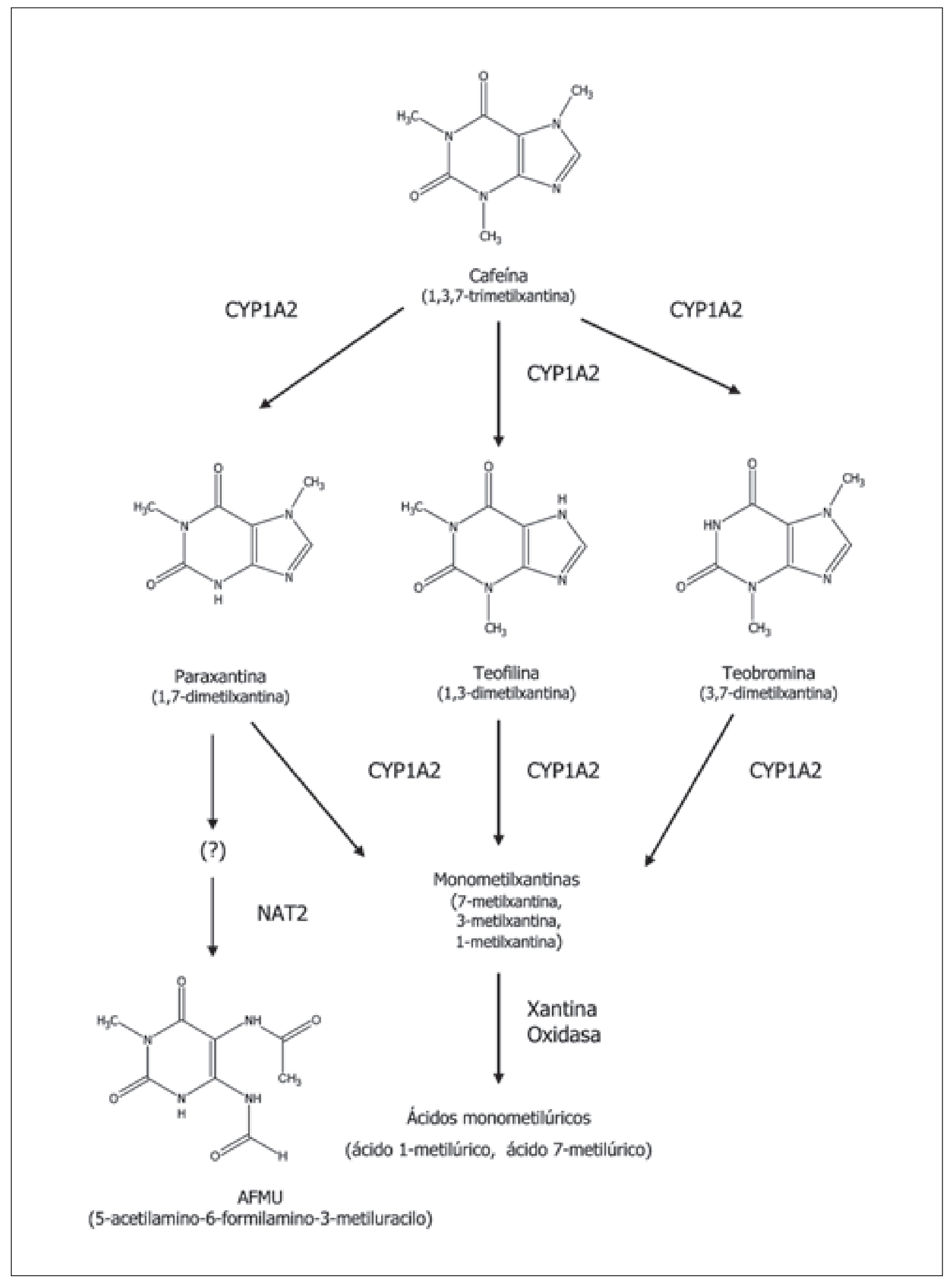


adversas en una persona y presentar buena tolerabilidad en otra. Los efectos adversos más frecuentes de la cafeína son palpitaciones, taquicardia, molestias gástricas, temblor, nerviosismo e insomnio ${ }^{11-13}$. Dosis elevadas pueden provocar intensa ansiedad, miedo y crisis de angustia. Se han descrito casos de psicosis aguda inducida por cafeína en personas sin psicopatología o de empeoramiento de síntomas psicóticos en esquizofrénicos ${ }^{48}$. Además, puede provocar anafilaxia ${ }^{49}$ y ser el alergeno causante de la urticaria de origen desconocido en consumidores de bebidas de cola ${ }^{50}$. Los efectos secundarios más frecuentes de la teofilina son gastrointestinales, neurológicos y cardiacos.

\section{EFECTOS INDESEABLES TRAS EXPOSICIÓN CRÓNICA}

En general, no existe una clara evidencia que el consumo moderado de cafeína cause un riesgo significativo para la salud en adultos sanos.

Cardiovasculares. La ingesta de cafeína no se ha relacionado directamente con el riesgo de hipertensión. A pesar de afectar el metabolismo lipidico ${ }^{21}$ y la función endotelial ${ }^{51}$, existen datos contradictorios sobre el aumento del riesgo de enfermedad coronaria ${ }^{52}$, contribuyendo ${ }^{53} \mathrm{o}$ no ${ }^{54}$ en la morbi-mortalidad.

Endocrinos. La mayor concentración de lípidos se obtiene con el café expreso, el café moka, el café turco y el café hervido. El café instantáneo y aquellos preparados con papel de filtro contienen menor nivel de estos lípidos ${ }^{1}$. La cafeína disminuye la densidad ósea ${ }^{55}$, si no se toman suplementos lácteos diarios ${ }^{56}$, porque podría potenciar la acción del receptor glucocorticoide, que es un factor de riesgo mayor para la osteoporosis ${ }^{57}$.El té no previene ni limita la ganancia de peso tras una pérdida de peso previa del 5-10\% en individuos con sobrepeso o peso moderado ${ }^{58}$.

Nefrourológicos. No se ha demostrado que produzca nefropatía por si misma ni un aumento de la nefropatía por analgésicos, como adyuvante de la analgesia ${ }^{59}$. La cafeína aumenta la excreción urinaria de calcio ${ }^{4}$ y es uno de los múltiples factores implicados en la incontinencia urinaria femenina ${ }^{60}$.

Digestivos. La cafeína estimula la secreción ácida gástrica y la actividad colónica. No está clara la asociación del uso de cafeína con las úlceras gástricas o duodenales. Sin embargo, el consumo de café exacerba el reflujo gastroesofágico, aunque este efecto podría estar causado por otros constituyentes del café diferentes a la cafeína 1,61.

Ginecológicos. El consumo de cafeína se ha asociado con el retraso de la concepción, aumento de la tasa de abortos espontáneos y la reducción del crecimiento fetal 4 .

Pediátricos. No se tiene información suficiente de sus efectos adversos a largo plazo en neonatos pretérmino ${ }^{62}$. En la población infantil y adolescente provoca cefalea diaria crónica, o incluso migraña sin aura, que desaparece al disminuir o cesar la ingesta ${ }^{63}$

Neurológicos. En algunos individuos, la cafeína causa sueño patológico porque produce sedación paradójica, un fenómeno idiosincrásico que también ha sido descrito con anfetaminas ${ }^{64}$. En cambio, la abstinencia de cafeína produce hipersomnia. (DSM-IV).

Psiquiátricos. La cafeína puede ocasionar ansiedad, crisis de angustia, abstinencia, dependencia y alteración del sueño ${ }^{12,13}$

Cancerígenos. La cafeína puede alterar las funciones de control del ciclo celular y varios mecanismos de reparación del DNA, pudiendo aumentar o antagonizar la exposición de potenciales mutagénicos y carcinógenos. Aunque los resultados son contradictorios se ha sugerido una relación entre el consumo de café y el cáncer de páncreas. Se ha descrito que la mutación del gen K-ras, marcador del cáncer de páncreas exocrino, aumenta de forma dosis dependiente el consumo de café ${ }^{65}$.

\section{INTOXICACIÓN}

Las intoxicaciones más frecuentes se dan en personas no consumidoras de cafeína, pero también se dan casos en usuarios que aumentan su dosis habitual o consumidores habituales de altas dosis de cafeína 12, 13,66. Los síntomas son una exageración de sus efectos farmacológicos, siendo los más frecuentes la taquicardia, inquietud, nerviosismo, temblor e insomnio. La intoxicación por cafeína puede no aparecer a pesar de la ingesta de grandes cantidades de cafeína debido al desarrollo de tolerancia ${ }^{67}$. Los criterios descritos DSM IV-TR para el diagnostico de la intoxicación por cafeína (cafeinismo) se describen en la tabla 2.

Otros signos descritos han sido coma con edema de pulmón, arrítmias (desde taquicardia a fibrilación auricular o ventricular) infarto de miocardio y rabdomiolisis ${ }^{4,68}$. La intoxicación en el neonato puede presentarse en forma de agitación, irritabilidad, hipertonía, sudoración, taquicardia, taquipnea, dilatación gástrica, insuficiencia cardiaca, edema de pulmón y alteraciones hidroelectrolíticas y metabólicas ${ }^{69}$. La dosis letal aguda de cafeína estimada en adultos estaría entre 5-10 g vía intravenosa u oral. Se han descrito casos mortales por intoxicación de cafeína ${ }^{70,72}$ e incluso un paciente que sobrevivió a $24 \mathrm{~g}^{4}$. 
A. Consumo reciente de cafeína, normalmente más de 250 mg (p. ej., más de 2-3 tazas de café).

B. Cinco (o más) de los siguientes signos, que aparecen durante o poco tiempo después del consumo de cafeína:
1. inquietud
2. nerviosismo
3. excitación
4. insomnio
5. rubefacción facial
6. diuresis
7. alteraciones digestivas
8. contracciones musculares
9. logorrea y pensamiento acelerado (como la intoxicación anfetamínica)
10. taquicardia o arritmia cardíaca
11. sensación de infatigabilidad
12. agitación psicomotora

C. Los síntomas de criterio B causan un malestar clínicamente significativo o un deterioro laboral o social, o de otras áreas importantes de la actividad del individuo.

D. Los síntomas no son debidos a enfermedad médica ni se explican mejor por la presencia de otro trastorno mental (p. ej., un trastorno de ansiedad).

La toxicidad crónica de cafeína puede manifestarse como miopatía, hipocalemia, debilidad muscular, nauseas, vómitos, diarrea y perdida de peso. La intoxicación aguda de teofilina va precedida por vómitos y la crónica por convulsiones y arritmias cardiacas ${ }^{4,72}$.

\section{UTILIZACIÓN TERAPÉUTICA DE LA CAFEÍNA Y POSIBLES EFECTOS BENEFICIOSOS DEL CAFÉ}

La teofilina se utiliza en adultos como broncodilatador de tercera elección en el asma y la enfermedad pulmonar obstructiva crónica. En Pediatría se emplea como broncodilatador y estimulante del SNC. Las metilxantinas son el tratamiento de primera elección en la apnea del recién nacido prematuro ${ }^{10,11}$. El citrato de cafeína debería ser el fármaco de primera elección en estos casos, porque presenta más ventajas que la teofilina a igual eficacia ${ }^{73}$. La cafeína se utiliza junto a analgésicos para potenciar la eficacia antiálgica y antimigrañosa. También está indicada en el tratamiento de la narcolepsia ${ }^{10,11}$

Se han sugerido distintas aplicaciones para la cafeína o el café, todas ellas deberán comprobase en el futuro en ensayos clínicos controlados.

Neurológicas. A pesar de no haberse demostrado una relación dosis respuesta ${ }^{74}$, la cafeína podría disminuir el riesgo de aparición de la enfermedad de Parkinson (EP) en hombres y en mujeres. El uso de estrógenos, incluso en histerectomizadas, impediría su efecto beneficioso ${ }^{75}$. No queda claro si la disminución del riesgo de la EP por la cafeína es independiente ${ }^{76}$ o no del tabaco y el alcohol. De ser así, se establecería las bases para el uso de antagonistas de receptores de adenosina $\mathrm{A} 2 \mathrm{~A}$ y agonistas nicotínicos en el tratamiento de la EP 77 . También se ha sugerido el uso de la cafeína en otras enfermedades neurodegenerativas: enfermedades de Alzheimer ${ }^{78}$ y de Huntington ${ }^{79}$.

Digestivas. Varios estudios caso-control han relacionado el consumo crónico de café con la reducción del riesgo de cáncer colorectal y de colon ${ }^{80}$, pero ningún estudio de cohortes lo ha confirmado ${ }^{81}$. Por otro lado, la cafeína disminuye los síntomas y el riesgo de desarrollar litiasis biliares, pero no se han descrito estos efectos en el café descafeinado, té y las colas ${ }^{24}$. Podría existir un ingrediente en el café que protege frente a la cirrosis, principalmente la de origen alcohólico ${ }^{82}$.

Endocrinas. Consumir café o chocolate negro ${ }^{83}$ podría aumentar la sensibilidad a la insulina y reducir el riesgo de diabetes tipo 2. Este efecto se atribuiría a sus diferentes componentes con capacidad antioxidante ${ }^{84}$. 
Ginecológicas. La cafeína podría aumentar la motilidad de los espermatozoides por lo que sería útil en pacientes con astenozoospermia ${ }^{85}$. No existen datos definitivos sobre la relación entre la cafeína y la patología mamaria. A altas dosis podría aumentar el riesgo de desarrollar hiperplasia atípica de mama ${ }^{86}$ o podría reducir el riesgo de cáncer de mama en las mujeres con la mutación en el gen BRCA ${ }^{87}$. El consumo de dos tazas de té diarios está asociado a una disminución del 46\% del riesgo de cáncer de ovario debido a los polifenoles presentes en el té verde y en el negro ${ }^{88}$.

Cáncer. La cafeína presenta efectos supresores sobre células tumorales en metástasis experimentales ${ }^{65}$. Esto sugiere que las metilxantinas podrían mejorar la clínica de la enfermedad metastásica reduciendo la morbimortalidad asociada ${ }^{89}$

\section{ASPECTOS GENÉTICOS}

La herencia genética explicaría entre un 35-77\% del consumo de cafeína ${ }^{90}$. Además, se ha demostrado la coexistencia de un factor genético común (policonsumidor), atribuyendo a la herencia el $28-41 \%$ de los efectos del uso o abuso del café compartido con los del uso del alcohol y del tabaco ${ }^{91,92}$. EL CYP1A2 presenta polimorfismo y los metabolizadores lentos de cafeína se han asociado con un aumento del riesgo de infarto de miocardio no fatal ${ }^{53}$.

\section{LA CAFEÍNA COMO DROGA DE ABUSO}

La consideración de la cafeína como droga de abuso es objeto de polémica. Así, mientras que la Clasificación Internacional de Enfermedades de la OMS considera la existencia de dependencia de cafeína, como también la de abstinencia e intoxicación, el DSM-IV-TR no reconoce la existencia de la dependencia y, aunque de forma inespecífica, sólo incluye en el capítulo de trastornos por uso de sustancias a la intoxicación por cafeína, dejando como trastorno en investigación la abstinencia.

Si se considera la definición de dependencia del DSM-IV-TR ${ }^{93}$ y se tienen en cuenta los siete criterios para cumplir el diagnóstico de dependencia, la cafeína podría considerarse como una droga de abuso. Así, en el caso de la cafeína se cumplen en la mayoría de grandes consumidores ${ }^{12,13,94}$ al menos tres de los criterios específicos, concretamente los de presencia de tolerancia, un síndrome de abstinencia específico, y el hecho de que la sustancia es tomada con frecuencia en cantidades mayores o durante un período más largo de lo que inicialmente se pretendía. Además la cafeína actúa como reforzador positivo y produce efectos placenteros o agradables, lo que conduce a la auto-administración ${ }^{12,13}$.

\section{Refuerzo positivo}

El refuerzo ocasionado por una droga es el principal responsable del patrón de consumo mantenido y de la dependencia a la sustancia ${ }^{95}$. El refuerzo que genera la cafeína se ha demostrado mediante la autoadministración intravenosa en animales y oral en humanos ${ }^{96-102}$. En estos últimos, los factores más importantes que podrían jugar un papel en el efecto reforzante de la cafeína son la forma de presentación, el olor, el sabor, el entorno social y la dosis ${ }^{100}$. El refuerzo se presenta en el $100 \%$ de los grandes consumidores de cafeína (1020-1530 mg /día) y en los sujetos con antecedentes de trastornos de abuso de alcohol y otras drogas. En cambio, es menos importante en aquellos consumidores moderados (128-595mg/día) ${ }^{66}$. Se ha sugerido que la autoadministración podría ser más una consecuencia de la búsqueda de alivio de la abstinencia que de los propios efectos reforzadores positivos. El café también actúa como reforzador. El mecanismo de refuerzo de la cafeína es diferente y de escasa potencia comparado con otros psicoestimulantes como la cocaína y las anfetaminas ${ }^{66}$.

Los humanos son capaces de discriminar entre la cafeína (en forma de cápsulas o de tazas de café) y el placebo. A dosis de 100 mg, entre un 30-60\% de los participantes discriminaron correctamente, mientras que tras 300 mg la mayoría de sujetos reconoció la cafeína adecuadamente. Mientras que a dosis bajas la discriminación se debía a los efectos psicoestimulantes positivos, a dosis altas la discriminación se debió a la aparición de efectos desagradables ${ }^{12,13,66}$.

\section{Tolerancia}

Se define como la necesidad de consumir una sustancia a dosis cada vez mayores que la inicial para producir un efecto reforzante similar al original o la reducción de ese efecto con las dosis iniciales ${ }^{93}$. La tolerancia a la cafeína suele ser un fenómeno de instauración rápida, de baja magnitud y cruzado con el de otras metilxantinas, pero con un mecanismo distinto al de otras drogas (anfetaminas y metilfenidato) ${ }^{103-105 . ~}$ El fenómeno de tolerancia se podría justificar por la acumulación no lineal de la cafeína y de sus principales metabolitos en modelos de dosis múltiple ${ }^{106}$. En humanos se ha demostrado tolerancia, en pocos días, a los efectos sobre la presión arterial, la frecuencia cardiaca y la diuresis a los niveles plasmáticos de adrenalina y noradrenalina y a la actividad de la renina. También 
existe tolerancia en las interrupciones y alteraciones del patrón del sueño ${ }^{12,13,106}$.

\section{Síndrome de abstinencia}

Es la dependencia psíquica o física (síntomas y signos) que presenta el sujeto por la supresión o disminución de la ingesta de cafeína. El síndrome de abstinencia de la cafeína está bien caracterizado y está clasificado como diagnóstico en el ICD-10. Además, existen suficientes evidencias empíricas para incluirlo como trastorno en investigación en el DSMIV-TR (Tabla 3) ${ }^{93}$
Se ha podido demostrar en animales la existencia de un síndrome de abstinencia al cesar la administración de dosis elevadas de cafeína. En diferentes estudios experimentales y encuestas de usuarios se ha podido demostrar que al cesar el consumo de cafeína aparece una sintomatología de abstinencia, que desaparece o se alivia al administrarla de nuevo. Se cree que el patrón de consumo de cafeína responde más a la evitación del síndrome de abstinencia que a sus posibles efectos reforzantes positivos, ya que dosis inferiores a $100 \mathrm{mg} / \mathrm{día}$ dan sintomatología. La sintomatología de la abstinencia se inicia aproximadamente

\section{Tabla 3. Criterios de investigación propuestos para el diagnóstico de la abstinencia de cafeína}

(DSM IV-TR).

A. Consumo diario de cafeína durante un período de tiempo prolongado.

B. Abandono o reducción súbitos del consumo de cafeína, seguido de dolores de cabeza y uno (o más) de los siguientes síntomas:

(1) fatiga o somnolencia acusadas

(2) ansiedad o depresión evidentes

(3) náuseas o vómitos

C. Los síntomas del Criterio B provocan malestar clínicamente significativo o deterioro social, laboral o de otras áreas importantes de la actividad del individuo.

D. Los síntomas no se deben a los efectos fisiológicos directos de una enfermedad médica (p. ej., migraña, enfermedad vírica) y no se explican mejor por la presencia de otro trastorno mental.

a las 12-24 horas de interrumpir el consumo, la máxima intensidad tiene lugar entre las 24-48 horas con una duración de 2-9 días. En general, la sintomatología es más intensa conforme la dosis diaria que se deja de consumir es mayor. La cefalea es el síntoma más frecuente. También se ha observado cansancio, fatiga y disminución del estado de alerta a corto y largo plazo. Estos síntomas son limitados en el tiempo y, generalmente, reversibles tras el consumo de cafeína ${ }^{66,107 .}$

La somnolencia y la disminución del bienestar y del deseo de socialización presentan un comportamiento similar en duración y reversibilidad. El humor depresivo, la dificultad para concentrarse, la irritabilidad y la desmotivación en el trabajo se presentan en menor grado.

Los signos más destacados asociados al cuadro de abstinencia son el deterioro cognitivo y de comportamiento, un aumento del flujo cerebral, cambios en el electroencefalograma, taquicardia, temblor de la mano y la disminución de la presión arterial, de la actividad motora y de la excreción de adrenalina en orina. Se ha evidenciado que las mujeres diagnosticadas de dependencia a la cafeína y una historia familiar de alcoholismo son más propensas a continuar consumiendo cafeína durante la gestación. Este hecho sugiere que el diagnóstico de dependencia a cafeína puede ser un marcador de la vulnerabilidad a la dependencia de otras drogas ${ }^{103}$.

Existen personas en las que el consumo de chocolate constituye un hábito que puede llegar a ser considerado popularmente casi como una adicción. Ya se ha comentado que el chocolate contiene además de teobromina y cafeína, anandamida (canabinoide endógeno), triptófano (precursor de la serotonina) y algunas feniletilaminas. Estas sustancias parecen ser las responsables de las propiedades placenteras y del abuso del chocolate.

Como hemos visto en esta editorial, la cafeína puede considerarse un fármaco, un nutriente y una droga de abuso, todo depende de cómo, cuánto y cuándo se use. 


\section{REFERENCIAS}

1 Moro MA, Lizasoain I, Ladero JM. Xantinas. En: Drogodependencias $2^{\text {a }}$ edición. Lorenzo P, Ladero JM, Leza JC, Lizasoain I, editores. Madrid: Panamericana; 2003. p. 255-62.

2 Arnaud MJ. The pharmacology of caffeine. Prog Drug Res 1987;31:273-313.

3 Smith BD, Gupta U, Gupta BS. Caffeine and activation theory. Effects on Health and Behavior. Boca Raton: CRC Press; 2007.

4 Nawrot P, Jordan S, Eastwood J, Rotstein J, Hugenholtz A, Feeley M. Effects of caffeine on human health. Food Addit Contam 2003;20:1-30.

5 Mandel HG. Update on caffeine consumption, disposition and action. Food Chem Toxicol. 2002; 40:1231-4

6 http://www.consumaseguridad.com/web/es/ normativa_legal/2003/06/30/7147.php\#bibliografia

7 http://news.bbc.co.uk/2/hi/health/1435409.stm

8 Ferreira SE, de Mello MT, Pompéia S, de SouzaFormigoni ML. Effects of energy drink ingestion on alcohol intoxication. Alcohol. Clin. Exp. Res 2006; 30:598-605

9 Ayesta FJ, Camí J. Farmacodependencias. Farmacologia Humana $4^{a}$ edición. Flórez J, Armijo JA, Mediavilla A, editores. Barcelona: Masson; 2003. p. 595-21.

10 Hurlé MA. Fármacos antiasmáticos y broncodilatadores. Farmacologia Humana $4^{a}$ edición. Flórez J, Armijo JÁ, Mediavilla A, editores. Barcelona: Masson; 2003. p. 729-43.

11 Underm BJ. Pharmacotherapy of asthma. Brunton LL, Lazo JS, Parker KL eds. Goodman \& Gilman. The Pharmacological Basis of Therapeutics. 11th ed. New Cork: McGrawHill; 2006. p. 717-36.

12 Ramos JA, Collazos F, Casas M. Metilxantinas. En: Manual de evaluación y tratamiento de drogodependencias. Bobes J, Casas M, Gutiérrez M, editores. Barcelona: Ars Médica; 2003. p. 335-42.

13 Ramos JA, Collazos F, Casas M. Adicciones a sustancias químicas (III). Psicoestimulantes. En: Tratado de Psiquiatría. Vallejo J, Leal C, editores. Barcelona: Ars Médica; 2005. p. 786-805.

14 Beaumont $M$, Batejat D, Coste O, Doireau P, Chauffard F, Enslen M, Lagarde D, Pierard C. Recovery after prolonged sleep deprivation: residual effects of slowrelease caffeine on recovery sleep, sleepiness and cognitive functions. Neuropsychobiology 2005;51:16-27.

15 Lindskog $M$, Svenningsson $P$, Pozzi L, Kim Y, Fienberg AA, Bibb JA, Fredholm BB, Nairn AC, Greengard P, Fisone $\mathrm{G}$.Involvement of DARPP-32 phosphorylation in the stimulant action of caffeine. Nature 2002;418:734-6.

16 Laska EM, Sunshine A, Mueller F, Elvers WB, Siegel C, Rubin A. Caffeine as an analgesic adjuvant. JAMA 1984;13:251.

17 Bara Al, Barley EA. Caffeine for asthma. Cochrane Database Syst Rev 2000;2:CD001112.
18 William R. Lovallo; Michael F. Wilson; Andrea S. Vincent; Bong Hee Sung; Barbara S. McKey; Thomas L. Whitsett. Blood Pressure Response to Caffeine Shows Incomplete Tolerance After Short-Term Regular Consumption. Hypertension 2004;43:760-765.

19 Taubert D, Roesen R, Lehmann C, Jung N, Scho“ mig E. Effects of Low Habitual Cocoa Intake on Blood Pressure and Bioactive Nitric Oxide. A Randomized Controlled Trial. JAMA 2007;298:49-60.

20 Lars Frost and Peter Vestergaard. Caffeine and risk of atrial fibrillation or flutter: the Danish Diet, Cancer, and Health Study. Am J Clin Nutrition 2005;81:578-82

21 Du Y; Melchert HU; Knopf H; Braemer-Hauth M; Gerding B; Pabel E. Association of serum caffeine concentrations with blood lipids in caffeine-drug users and nonusers - Results of German National Health Surveys from 1984 to 1999. Europ J Epidem 2005;20:311-6.

22 Cheung RJ Gupta EK, Ito MK. Acute Coffee Ingestion Does Not Affect LDL Cholesterol Level. Ann Pharmacother 2005;39:1209-13.

23 Rob M. van Dam, Wilrike J. Pasman, Petra Verhoef. Effects of Coffee Consumption on Fasting Blood Glucose and Insulin Concentrations. Randomized controlled trials in healthy volunteers. Diabetes Care 2004;27:2990-2.

24 Tianying Wu, Walter C. Willett, Susan E. Hankinson, Edward Giovannucci. Caffeinated Coffee, Decaffeinated Coffee, and Caffeine in Relation to Plasma C-Peptide Levels, a Marker of Insulin Secretion, in U.S. Women. Diabetes Care 2005;28:1390-6.

25 Gottlieb S. More coffee, fewer gallstones.BMJ 1999;318:1646.

26 Chandrasekaran S; Rochtchina E. Effects of Caffeine on Intraocular Pressure: The Blue Mountains Eye Study. J Glaucoma 2005;14:504-7.

27 Jong Weon Choi. Influence of caffeine on the responsiveness of human platelet to agonists. Thrombosis Research 2003;110:209-12.

28 Christian MS, Brent RL.Teratogen update: evaluation of the reproductive and developmental risks of caffeine. Teratology 2001;64:51-78.

29 Alison Taylor. ABC of subfertility. BMJ 2003;327:434-6.

30 Mildred S. Christian, Robert L. Brent. Teratogen update: Evaluation of the reproductive and developmental risks of caffeine. Teratology 2001;64:51-78.

31 J. L. Mills, L. B. Holmes, J. H. Aarons, J. L. Simpson, Z. A. Brown, L. G. Jovanovic et al. Moderate caffeine use and the risk of spontaneous abortion and intrauterine growth retardation. JAMA 1993;269:593-7.

32 Giannelli M.; Doyle P.; Roman E.; Pelerin M.; Hermon C. The effect of caffeine consumption and nausea on the risk of miscarriage. Paediatric \& Perinatal Epidemiology 2003;17:316-23.

33 Fetal loss associated with caffeine intake before and during pregnancy. C. Infante-Rivard, A. Fernandez, R. Gauthier, M. David and G. E. Rivard. JAMA 1993;270(24). 
34 Sven Cnattingius, Lisa B. Signorello, Göran Annerén, Britt Clausson, Anders Ekbom, Elisabeth Ljunger et al. Caffeine Intake and the Risk of FirstTrimester Spontaneous Abortion. New Engl J Med 2000;343:1839-45.

35 Fumihiro Sata, Hideto Yamada, Kana Suzuki, Yasuaki Saijo, Emi H Kato, Mamoru Morikawa et al. Caffeine intake, CYP1A2 polymorphism and the risk of recurrent pregnancy loss. Mol Hum Reprod 2005;11:357-60.

36 Michael B. Bracken; Elizabeth W. Triche; Kathleen Belanger; Karen Hellenbrand; Brian P. Leaderer. Association of Maternal Caffeine Consumption with Decrements in Fetal Growth American J Epidem 2003;157:456-66.

37 Derek G Cook, Janet L Peacock, Colin Feyerabend, Iain M Carey, Martin J Jarvis, H Ross Anderson et al. Relation of caffeine intake and blood caffeine concentrations during pregnancy to fetal growth: prospective population based study. BMJ 1996; 313:1358-62.

38 Janet L Peacock, J Martin Bland, H Ross Anderson. Preterm delivery: effects of socioeconomic factors, psychological stress, smoking, alcohol, and caffeine. BMJ 1995;311:531-5.

39 Donovan JL, DeVane CL. A primer on caffeine pharmacology and its drug interactions in clinical psychopharmacology. Psychopharmacol Bull 2001; 35:30-48.

40 Fuhr U, Rost KL. Simple and reliable CYP1A2 phenotyping by the paraxanthine/caffeine ratio in plasma and in saliva. Pharmacogenetics 1994; 4:109-16.

41 Carrillo JA, Benitez J. Clinically significant pharmacokinetic interactions between dietary caffeine and medications. Clin Pharmacokinet 2000; 39:127-53.

42 Swanson JA, Lee JW, Hopp JW, Berk LS.The impact of caffeine use on tobacco cessation and withdrawal. Addict Behav. 1997;22:55-68.

43 Kari R, Virpi R, Jouko L, Pertti N. Effect of CaffeineContaining versus Decaffeinated Coffee on Serum Clozapine Concentrations in Hospitalised Patients Basic Clin Pharmacol Toxicol 2004;94:13-8.

44 Shioda K, Nisijima K, Nishida S, Kato S. Possible serotonin syndrome arising from an interaction between caffeine and serotonergic antidepressants. Hum Psychopharmacol Clin Exp 2004;19:353-4.

45 Jones HE, Griffiths RR. Oral caffeine maintenance potentiates the reinforcing and stimulant subjective effects of intravenous nicotine in cigarette smokers. Psychopharmacology (Berl). 2003;165:280-90.

46 Hughes JR, Oliveto AH. Coffee and alcohol intake as predictors of smoking cessation and tobacco withdrawal. J Subst Abuse 1993;5:305-10.

47 Brenda Eskenazi. Caffeine Filtering the Facts. NEJM 1999;22:1688-1689.

48 Broderick P, Benjamin AB. Caffeine and psychiatric symptoms: a review. J Okla State Med Assoc. 2004;97:538-42.
49 S. Infante, M. L. Baeza, M. Calvo, M. De Barrio, M. Rubio, T. Herrero. Anafilaxia por cafeína. Allergy 2003; 58:680-690

50 M. Fernández-Nieto, J. Sastre, S. Quince. Urticaria from coke. Allergy 2002;57:967.

51 Papamichael CM, Aznaouridis KA, Karatzis EN, Karatzi KN, Stamatelopoulos KS, Vamvakou G, et al. Effect of coffee on endothelial function in healthy subjects: the role of caffeine. Clin Sci 2005;109:55-60.

52 Editorial. Coffee intake and death from coronary heart disease. BMJ 1996;312:1539

53 Cornelis MC, El-Sohemy A, Kabagambe EK, Campos H. Coffee, CYP1A2 Genotype, and Risk of Myocardial Infarction. JAMA. 2006;295:1135-41

54 Willett WC, Stampfer MJ, Manson JE, Colditz GA, Rosner BA, Speizer FE, Hennekens CH. Coffee consumption and coronary heart disease in women. $A$ ten-year follow-up. JAMA 1996;275:458-62

55 Compston JE, Cooper C, Kanis JA. Fortnightly Review: Bone densitometry in clinical practice. BMJ 1995;310:1507-1510.

56 Barrett-Connor E, Chang JC, Edelstein SL. Coffeeassociated osteoporosis offset by daily milk consumption. The Rancho Bernardo Study. JAMA 1994; 271:280-3.

57 Focking M, Schmiegelt D, Trapp T. Caffeine-mediated enhancement of glucocorticoid receptor activity in human osteoblastic cells. Biochem Biophys Res Commun. 2005;337:435-9.

58 Kovacs EMR, Lejeune MPGM, Nijs I, WesterterpPlantenga MS. Effects of green tea on weight maintenance after body-weight loss. Br. J. Nutr. 2004; 91:431-7.

59 Zhang WY. A benefit-risk assessment of caffeine as an analgesic adjuvant. Drug Saf 2001;24:1127-42.

60 Jayna M. Holroyd-Leduc, Sharon E. Straus. Management of Urinary Incontinence in Women. JAMA2004; 291:986-995

61 Wendl B, Pfeiffer A, Pehl C, Schmidt T, Kaess $H$. Effect of decaffeination of coffee or tea on gastrooesophageal reflux. Aliment Pharmacol Ther 1994; 8:283-287.

62 Henderson-Smart DJ, Davis PG.Prophylactic methylxanthines for extubation in preterm infants. Cochrane Database Syst Rev. 2003;1:CD000139.

63 Hering-Hanit R; Gadoth N. Caffeine-induced headache in children and adolescents. Cephalalgia, 2003; 23:332-335

64 Regestein QR. Pathologic sleepiness induced by caffeine. Am J Med 1989; 87:586-588.

65 Porta M, Vioque J, Ayude D, Alguacil J, Jariod M, Ruiz $L$ et al. Coffee drinking: the rationale for treating it as a potential effect modifier of carcinogenic exposures. Eur J Epidemiol 2003; 18:289-298.

66 Juliano LM, Griffiths RR. Caffeine. In: Lowinson JH, Ruiz P, Millman RB, Langrod JG, editors. Substance Abuse. A Comprehensive Textbook. Philadelphia: Lippincott Williams \& Wilkins; 2005. p. 403-421. 
67 Pentel P. Toxicity of over-the-counter stimulants. JAMA 1984;252:1898-903.

68 Donnerstein RL, Zhu D, Samson R, Bender AM, Goldberg SJ. Acute effects of caffeine ingestion on signal-averaged electrocardiograms. Am Heart J. 1998;136:574-5.

69 Ergenekon E, Dalgic N, Aksoy E, Koc E, Atalay Y. Caffeine intoxication in a premature neonate. Paediatr Anaesth. 2001;11:737-9.

70 Holmgren P, Norden-Pettersson L, Ahlner J. Caffeine fatalities-four case reports. Forensic Science International 2004;139:71-73.

71 Kerrigan S, Lindsey T. Fatal caffeine overdose: two case reports. Forensic Sci Int. 2005;153:67-9.

72 Rice JE, Faunt JD. Excessive cola consumption as a cause of hypokalaemic myopathy. Int Med J 2001; 31:317-8

73 Bhatia J. Current options in the management of apnea of prematurity. Clin Pediatr (Phila) 2000;39:327-36.

74 Anonymous. Relationship Between Caffeine Intake and Parkinson Disease. JAMA 2000;284:1378-7.

75 Ascherio A, Weisskopf MG, O'Reilly EJ, McCullough $\mathrm{ML}$, Calle EE, Rodriguez $\mathrm{C}$ et al. Coffee consumption, gender, and Parkinson's disease mortality in the Cancer prevention Study II Cohort: The Modifying Effects of Estrogen. Am J Epidem 2004;160:977-84.

76 Ross GW, Abbott RD, Petrovitch H, Morens DM, Grandinetti A, Tung KH, Tanner CM, Masaki KH, Blanchette PL, Curb JD, Popper JS, White LR. Association of coffee and caffeine intake with the risk of Parkinson disease. JAMA 2000;283:2674-6.

77 Chen JF, Xu K, Petzer JP, Staal R, Xu YH, Beilstein M et al.Neuroprotection by caffeine and $A(2 A)$ adenosine receptor inactivation in a model of Parkinson's disease. J Neurosci. 2001;21:RC143.

78 Dall'Igna OP, Porciúncula LO, Souza DO, Cunha RA and Lara DR. Neuroprotection by caffeine and adenosine A2A receptor blockade of -amyloid neurotoxicity. British Journal of Pharmacology 2003;138:1207-9

79 Fink JS, Kalda A, Ryu H, Stack EC, Schwarzschild MA, Chen JF et al. Genetic and pharmacological inactivation of the adenosine $\mathrm{A} 2 \mathrm{~A}$ receptor attenuates 3-nitropropionic acid-induced striatal damage. J Neurochem 2004;88:538-44.

80 Karin B. Michels; Walter C. Willett; Charles S. Fuchs; Edward Giovannucci. Coffee, Tea, and Caffeine Consumption and Incidence of Colon and Rectal Cancer. Journal of the National Cancer Institute. 2005; 97:282-92.

81 Alessandra TAVANI, Alberto PREGNOLATO, Carlo LA VECCHIA, Eva NEGRI, Renato TALAMINI and Silvia FRANCESCHI. Coffee and tea intake and risk of cancers of the colon and rectum: a study of 3,530 cases and 7,057 controls. Int. J. Cancer 1997;73:193-7

82 Klatsky AL, Morton C, Udaltsova N, Friedman GD. Coffee, cirrhosis, and transaminase enzymes. Arch Intern Med 2006;166:1190-5
83 Grassi D, Lippi C, Necozione S, Desideri G, Ferri C. Short-term administration of dark chocolate is followed by a significant increase in insulin sensitivity and a decrease in blood pressure in healthy persons. Am J Clin Nutrition 2005;81:611-4.

84 Van Dam RB, Hu FB. Coffee Consumption and Risk of Type 2 Diabetes. JAMA. 2005;294:97-104.

85 Pasqualotto FF, Lucon AM, Sobreiro BP, Hallak J, Pasqualotto EB, Arap S. Does caffeine intake impair semen quality and hormonal levels in a fertile population?. Fertility and Sterility 2003;80:231-3.

86 Penelope M. Webb, Celia Byrne, Stuart J. Schnitt, James L. Connolly, Timothy W. Jacobs, Heather J. Baer et al. A Prospective Study of Diet and Benign Breast Disease. Cancer Epidemiol Biomarkers Prev 2004;13:1106-13.

87 André Nkondjock, Parviz Ghadirian, Joanne Kotsopoulos, Jan Lubinski, Henry Lynch, Charmaine Kim et al. Coffee consumption and breast cancer risk among BRCA1 and BRCA2 mutation carriers. Internacional Journal of Cancer 2005; 118:103-7.

88 Larsson SC, Wolk A. Tea consumption and ovarian cancer risk in a population-based cohort. Arch Intern Med 2005; 165:2683-6

89 Yang, Haiyan; Rouse, Jessica; Lukes, Luanne; Lancaster, Mindy; Veenstra, Timothy; Zhou, Ming et al. Caffeine suppresses metastasis in a transgenic mouse model: a prototype molecule for prophylaxis of metastasis. Clin. Exp Metastasis. 2004;21:719-35.

90 Kendler KS, Prescott CA. Caffeine intake, tolerance, and withdrawal in women: a population-based twin study. Am J Psychiatry 1999; 156:223-228.

91 Swan GE, Carmelli D, Cardon LR. Heavy consumption of cigarettes, alcohol and coffee in male twins. J Stud Alcohol 1997; 58:182-90.

92 Hettema JM, Corey LA, Kendler KS. A multivariate genetic analysis of the use of tobacco, alcohol, and caffeine in a population based sample of male and female twins. Drug Alcohol Depend 1999;57:69-78.

93 American Psychiatric Association DSM-IV-TR. Manual diagnóstico y estadístico de los trastornos mentales IV - Texto revisado. Barcelona: Elsevier-Masson; 2001.

94 Strain EC, Mumford GK, Silverman K, Griffiths RR. Caffeine dependence syndrome. Evidence from case histories and experimental evalations. JAMA 1994;272:1065-6.

95 Nehlig A. Are we dependent upon coffee and caffeine? A review on human and animal data. Neurosci Biobehav Rev 1999;23:563-76.

96 Stern KN, Chait LD, Johanson CE. Reinforcing and subjective effects of caffeine in normal human volunteers. Psychopharmacology 1989;98:81-8.

97 Griffiths RR, Bigelow GE, Liebson IA. Human coffee drinking: reinforcing and physical dependence producing effects of caffeine. J Pharmacol Exp Ther 1986;239: 416-25.

98 Griffiths RR, Bigelow GE, Liebson IA, O'Keffe M, O’Leary D, Russ N. Human coffee drinking: 
manipulation of concentration and caffeine dose. $J$ Exp Anal Behav 1986;45:133-48.

99 Griffiths RR, Bigelow GE, Liebson IA. Reinforcing effects of caffeine in coffee and capsules. J Exp Anal Behav 1989;52:127-40.

100 Hughes JR, Higgins ST, Bickel WK, Hunt WK, Fenwick JW, Gulliver SB, Mireault GC. Caffeine selfadmistration, withdrawal, and adverse effects among coffee drinkers. Arch Gen Psychiatry 1991;48:611-7.

101 Hughes JR, Hunt WK, Higgins ST, Bickel WK, Fenwick JW, Pepper SL. Effect of dose on the ability of caffeine to serve as a reinforcer in humans. Behav Pharmacol 1992;3:211-8.

102 Oliveto AH, Hughes JR, Pepper SL, Bickel WK, Higgins ST. Low doses of caffeine can serve as reinforcers in humans. NIDA Res Monogr 1991;105:442.

103 Griffiths RR, Woodson PP. Caffeine physical dependence: a review of human and laboratory animal studies. Psychopharmacology 1988;94:437-51.
104 Shi J, Benowitz NL, Denaro CP, Sheiner LB. Pharmacolinetic-pharmacodynamic modelling of caffeine: tolerance to pressor effects. Clin Pharmacol Ther 1993;53:6-14.

105 Eddy NB, Downs AW. Tolerance and cross-tolerance in the human subject to the diuretic effect of caffeine, theobromine and theophylline. J Pharmacol Exp Ther 1928;33:345-9.

106 Denaro CP, Brown CR, Wilson M, Jacob III P, Benowitz NL. Dose-dependency of caffeine metabolism. Clin Pharmacol Ther 1990;31:277-85.

107 Juliano LM, Griffiths RR. A critical review of caffeine withdrawal: empirical validation of symptoms and signs, incidence, severity, and associated features. Psychopharmacology (Berl). 2004;176:1-29. 